\title{
Fichte frente a Spinoza: \\ la Doctrina de la ciencia como vía de reconciliación
}

\section{Fichte on Spinoza: The Doctrine of Knowledge as a Way for Reconciliation}

\author{
MARÍA JIMENA SOLÉ \\ Conicet - Universidad de Buenos Aires \\ Recibido: 01/03/2016 Aceptado:09/03/2016
}

\begin{abstract}
RESUMEN
Este artículo ofrece un análisis de la interpretación que hace Fichte de la filosofía spinoziana en su Grundlage des gesamten Wissenschaftslehre (1794) para determinar por qué Spinoza es uno de sus interlocutores privilegiados en esta obra. Mi propuestas es Fichte considera esta doctrina como el máximo representante de una posición (el dogmatismo) que debe ser completada, no refutada. La Doctrina de la ciencia fichteana (idealismo práctico) es una vía para la reconciliación de dos posturas aparentemente incompatibles: el determinismo y la libertad. Teniendo en cuenta el contexto problemático más amplio en que surge este sistema, sostengo que no es Spinoza el auténtico enemigo de Fichte, sino Jacobi.
\end{abstract}

PALABRAS CLAVE:

DOGMATISMO, IDEALISMO, LIBERTAD, SANO ENTENDIMIENTO HUMANO, POLÉMICA DEL SPINOZISMO

\footnotetext{
ABSTRACT

This article offers an analysis of Fichte's interpretation of Spinoza's philosophy in his Grundlage des gesamten Wissenschaftslehre (1794) in order to determine why Spinoza is one of his privileged interlocutors in this work. My proposal is that Fichte considered this doctrine as the maximum representative of a position (dogmatism) that must be completed, not refuted.

(C) Contrastes. Revista Internacional de Filosofía, vol. XXII-N ${ }^{\circ} 1$ (2017), pp. 155-171. ISSN: 1136-4076

Departamento de Filosofía, Universidad de Málaga, Facultad de Filosofía y Letras Campus de Teatinos, E-29071 Málaga (España)
} 
Fichte's Doctrine of Science (practical idealism) is thus a way for the reconciliation of two apparently incompatible positions: determinism and freedom. Taking into account the broader problematic context in which this system emerges, I argue that Spinoza is not Fichte's real enemy, but Jacobi.

\section{KEYWORDS \\ DOGMATISM, IDEALISM, FREEDOM, COMMON HUMAN UNDERSTANDING, SPINOZISM CONTROVERSY}

Spinoza es uno de los filósofos a los que Fichte hace mención con más frecuencia en sus escritos y la confrontación con el sistema spinoziano puede rastrearse a lo largo de toda su obra. ${ }^{1}$ El principal reproche de Fichte a Spinoza consiste en señalar que su sistema es dogmático y, por lo tanto, opuesto e incompatible con el idealismo que él defiende. Sin embargo, Fichte señala también sus aciertos. Reconoce que si Spinoza ha sido un dogmático, lo ha sido de un modo que lo hace sobresalir, pues su sistema representa la consumación del dogmatismo, su versión más consecuente. Además, a pesar de ello, Fichte está dispuesto a admitir ciertas coincidencias entre ellos, en cuanto al punto de vista adoptado, la motivación que los impulsa y el tipo de unidad que buscan.

Fichte asume, por lo tanto, una posición ambivalente. Por un lado, Spinoza parece ser un adversario filosófico al que es necesario vencer. Por otro lado, sus aciertos teóricos hacen que Fichte le reconozca una función positiva, fecunda en relación a su Doctrina de la ciencia, tal como lo expresa en una carta de 1795 a Reinhold. A partir del sistema de Spinoza, sostiene allí, el suyo propio «puede ser explicado de la manera más adecuada». ${ }^{2}$ Años más tarde, en el texto de la última versión de su sistema de 1812, Fichte vuelve a declarar que el sistema de Spinoza es el mejor punto de partida para ingresar a la Doctrina de la ciencia. ${ }^{3}$

No es, pues, de extrañar que la relación entre ambos y el papel que la filosofía de Spinoza juega en la gestación y el desarrollo de la Doctrina de la ciencia, hayan motivado el interés de los especialistas. Los escritos dedicados a este tema publicados en los últimos años confirman que este interés no ha desaparecido. ${ }^{4}$

1 Cf. Lauth 1978, pp. 33-34; también Ivaldo 1992, pp. 59-60.

2 Carta de Fichte a Reinhold, del 2 de julio de 1795 en Fichte, J. G. 1962 y ss.: Gesamtausgabe der Bayerischen Akademie der Wissenschaften, 40 tomos. Ed. por Reinhard Lauth, Erich Fuchs y Hans Gliwitzky, Stuttgart-Bad Cannstatt: Frommann-Holzboog. Tomo III,2, p. 348. Cito las obras de Fichte según esta edición que, como es habitual, se indica con las siglas GA.

3 GA I.10, p. 326.

4 Entre la bibliografía más reciente dedicada a esta cuestión se destacan los artículos de Armin 2015, Beiser 2015, Gaudio 2015 y Haag 2012. 
Mi objetivo en las siguientes páginas es concentrarme en el momento inaugural de esta confrontación, plasmado en el texto que expone públicamente la primera versión acabada del sistema fichteano: la Fundamentación de toda la Doctrina de la ciencia de 1794/5. ${ }^{5}$ Este texto aborda la figura de Spinoza en numerosas ocasiones, transformándolo en uno de sus interlocutores privilegiados. En efecto, entre los pocos filósofos a los que encontramos una referencia explícita, Spinoza es -después de Kant- el más citado.

Frente a la variedad de enfoques que los expertos han asumido ante esta compleja relación, mi intención no es buscar similitudes entre Fichte y Spinoza,${ }^{6}$ ni seguir la huella de una influencia directa del spinozismo en la génesis de la doctrina fichteana, ${ }^{7}$ ni tampoco juzgar si la lectura que Fichte hace de este sistema es correcta. ${ }^{8}$ Mi propuesta consiste en realizar, en primer lugar, un análisis de la interpretación que Fichte ofrece de Spinoza en la GWL, con el fin de reconstruir únicamente a partir de este texto la manera en la que Fichte considera al sistema spinoziano hacia 1794. En segundo lugar, basándome en las conclusiones del primer punto y tomando en cuenta el contexto problemático más amplio de surgimiento de la Doctrina de la ciencia -especialmente la Polémica del spinozismo-, propongo intentar responder a

5 Fichte, J. G., Grundlage der gesamten Wissenschaftslehre, Jena, 1794. Segunda parte: 1795. Remitiré a esta obra con las siglas GWL. Traducción al español: Fichte 1975: Fundamentación de toda la Doctrina de la ciencia. Trad., introducción y notas de J. Cruz Cruz. Buenos Aires: Aguilar. Para hacer referencia a esta traducción, utilizo las siglas FDC.

6 La discusión acerca de si Fichte fue o no un spinozista, tiene una larga historia. En 1799, en el contexto de la Polémica del ateísmo, La Doctrina de la ciencia fue denunciada por Jacobi como una forma invertida del sistema de Spinoza. De algún modo, toda la producción posterior de Fichte puede ser vista como un intento por rechazar esta acusación. Acerca de este episodio, puede verse Rivera de Rosales y Cubo (2010).

7 Una investigación de este tipo ha sido recientemente llevada adelante, no sin dificultades desde el punto de vista metodológico, por Guilherme 2009.

8 Lauth establece que Fichte pertenece a una generación de pensadores que no atribuían ningún valor a la erudición filológica. Su interés era el de resolver sistemáticamente las cuestiones filosóficas que se planteaban sin apelar a autoridades exteriores ( $c f$. Lauth 1978, p. 30). Así, Lauth señala que Fichte sostuvo en sus Lecciones sobre Metafisica que abordan el sistema de Spinoza, que su intención es la de reconstruir esta filosofía según lo que él interpreta que es su espíritu, no según la letra (véase GA II.4, p. 244 y GA IV.1, p. 366; Lauth 1978, p. 31). En este sentido, Ivaldo señala que Fichte no quiere hacer una reconstrucción histórica de la obra de Spinoza, sino que quiere lograr una comprensión consecuente de la lógica inmanente de ese sistema (Ivaldo 1992, p. 62). 
la cuestión de por qué Spinoza es un interlocutor privilegiado en esta primera exposición publicada de su sistema.

\section{LA INTERPRETACIÓN DE SPINOZA EN LA GWL}

La discusión con Spinoza comienza en uno de los escolios que Fichte introduce luego de la deducción del primer principio de la Doctrina de la ciencia, el Yo absoluto que expresa la Thathandlung, la pura actividad de ponerse a sí mismo. El objetivo principal de este pasaje parece ser mostrar las diferencias que existen entre este axioma fundamental y los principios establecidos por otros filósofos antes que él y que podrían ser considerados como similares. Fichte se ocupa entonces de Kant, de Descartes, de Reinhold y finalmente de Spinoza, cuya posición analiza con un detenimiento considerablemente mayor. La lectura que Fichte ofrece aquí, condensada en unos pocos párrafos, puede resumirse en tres tesis acerca del spinozismo, a las que realiza tres objeciones.

La primera tesis, que algunos intérpretes suelen considerar como la posición definitiva de Fichte frente al spinozismo, consiste en la afirmación de que Spinoza «ha ido más allá» ${ }^{9}$ del primer axioma de la Doctrina de la ciencia. Para explicar la existencia del yo empírico, Spinoza recurre a «algo fuera del Yo». ${ }^{10}$ Contra esta posición, Fichte objeta que esta búsqueda del fundamento más allá del Yo introduce una separación entre la conciencia empírica y la conciencia pura, que implica la imposibilidad de explicar la autoconciencia.

Este primer punto de la confrontación con el spinozismo permite a Fichte explicitar un aspecto fundamental de su propia posición. Según Fichte, la única manera de explicar la autoconciencia empírica -que es, precisamente la tarea de la filosofía- es elevándose al ámbito de la autoconciencia pura, donde sujeto y objeto no están todavía escindidos. Precisamente, el Yo absoluto que se pone a sí mismo es, según Fichte, «necesariamente identidad de sujeto y objeto: sujeto-objeto: y es tal absolutamente sin ulterior mediación». ${ }^{11}$ Pero ese Yo absoluto no puede estar separado, más allá del Yo empírico en el que la representación efectivamente sucede, sino que éste tiene que poder acceder a esa acción originaria de autoposición -ya sea mediante el proceso de reflexión abstractiva que Fichte utiliza en la GWL, ya sea mediante la intuición intelectual, que incorpora en las versiones posteriores de su sistema. El Yo absoluto debe estar puesto en el Yo empírico como su fundamento, de modo que el acceso al primer principio fundamental de la Doctrina de la ciencia se da en el ámbito de la propia autoconciencia. Separarlos, como ha hecho Spinoza, impi-

9 GA I.2, p. 263. FDC, pp. 19-20.

10 GA I.2, p. 263. FDC, p. 20.

11 GA I.2, p. 261. FDC, p. 18, nota al pie. 
de dar esta explicación de la autoconciencia y las propias representaciones. ${ }^{12}$

En segundo lugar, Fichte afirma que el sistema de Spinoza es «plenamente consecuente e irrefutable». Esto, que parece contradecir la tesis anterior, se sigue en realidad de ella. El sistema spinoziano es irrefutable porque «se desenvuelve en un terreno en donde la razón no puede seguirlo $[\ldots] \gg .{ }^{13} \mathrm{La}$ objeción de Fichte consiste en señalar que,_por rebasar la conciencia pura que se da en la conciencia empírica y establecer un principio que está más allá sin ofrecer ningún argumento racional ni ninguna demostración que lo justifique, el sistema spinoziano «carece de fundamento». ${ }^{14}$

Este segundo aspecto de la confrontación con el spinozismo también permite a Fichte poner en claro un aspecto central de su propio sistema. En efecto, el Yo absoluto, el primer principio de la Doctrina de la ciencia, no es afirmado arbitrariamente, sino que la posición del Yo puro como primer principio fundamental es el resultado de un procedimiento de reflexión abstractiva que busca las condiciones trascendentales que hacen posible la conciencia. El primer principio de la Doctrina de la ciencia es objeto de una deducción trascendental y por eso constituye un auténtico fundamento.

Finalmente, Fichte afirma que el sistema spinoziano es el resultado de la búsqueda de la unidad más alta en el conocimiento humano, la cual «está presente en su sistema». ${ }^{15}$ Spinoza es, según su opinión, un pensador especulativo que se pregunta por el fundamento de la experiencia y logra elevarse a la unidad suprema -unidad que, afirma, «volveremos a encontrar» en la Doctrina de la ciencia- ${ }^{16}$ Sin embargo, se apresura a indicar la diferencia entre ellos y explicita una tercera objeción. Según Fichte, Spinoza se confunde al creer que esa unidad es el resultado del ejercicio de la razón teórica y no ver que se trata de una necesidad práctica. Mientras que la sustancia spinoziana es establecida como algo efectivamente dado, como algo que es, el primer principio de la Doctrina de la ciencia es un ideal propuesto como meta, como algo que debe ser. El error de Spinoza «consiste en haber creído concluir según fundamentos racionales, cuando realmente era empujado por una necesidad de orden práctico $[\ldots] \gg .{ }^{17}$

De este modo, la confrontación con Spinoza permite a Fichte enfatizar también el carácter ideal de su primer principio, que no debe ser comprendido

12 Acerca de este punto, véase el artículo de Haag 2012.

13 GA I,2, p. 263. FDC, p. 20.

14 Ibid.

15 Ibid.

16 Este punto representa el reconocimiento por parte de Fichte de una importante coincidencia entre la Doctrina de la ciencia y el sistema de Spinoza: el rechazo del dualismo y la postulación de un principio explicativo único ( $c f$. Ivaldo 1992, p. 63).

17 GA I.2, p. 263. FDC, p. 20. 
como un ser existente efectivamente, como una cosa, como una causa primera. El Yo absoluto no es, sino que debe ser -a pesar de que su realización efectiva, advierte Fichte, sea imposible.

Esta caracterización del spinozismo como un sistema especulativo, que busca la unidad suprema del saber humano pero se confunde al ponerla en una sustancia existente por sí y en sí, conduce a Fichte a concluir que «necesariamente hay que llegar al spinozismo si se va más allá del Yo soy». ${ }^{18}$ Cualquiera que pretenda sobrepasar el primer principio de la Doctrina de la ciencia debe aceptar necesariamente el spinozismo. Para probarlo, Fichte remite a Salomon Maimon quien «ha demostrado que el sistema de Leibniz, rigurosamente desarrollado, no era diferente del spinozismo». ${ }^{19}$ Por lo tanto, concluye, «solamente hay dos sistemas verdaderamente consecuentes: el criticismo, que reconoce este límite, y el spinozismo, que se lo salta». ${ }^{20}$

La diferencia entre el spinozismo y el criticismo reside, pues, en que adoptan principios fundamentales opuestos: la sustancia y el Yo. En este punto, Spinoza parece perfilarse como el principal adversario de la Doctrina de la ciencia, como el autor del único sistema que vale la pena refutar, pues representa una alternativa filosófica igualmente válida, pero se opone completamente a ella. ${ }^{21}$

Sin embargo, cuando Fichte retoma esta conclusión y vuelve a ocuparse de Spinoza pocas páginas más adelante, luego de haber establecido los otros dos principios de su sistema, no encontramos una refutación del spinozismo, ni tampoco nuevas objeciones que pongan de manifiesto la falsedad de su sistema. Por el contrario, Fichte enriquece su lectura con dos nuevas tesis, de modo que la relación que había planteado entre la Doctrina de la ciencia y el spinozismo se modifica radicalmente y éste ya no aparece, en realidad, como un adversario.

«La esencia de la filosofía crítica», comienza diciendo Fichte en este nuevo pasaje en el que se ocupa de Spinoza, «consiste en establecer un Yo absoluto,

18 Ibid.

19 Ibid. Fichte remite a una disertación de Maimon titulada Sobre los progresos de la Filosofía, incluida en Streiferein im Gebiete der Philosophie [Incursiones en el ámbito de la filosofia], I parte, Berlín, 1793. La relación entre las posiciones de Leibniz y Spinoza ya había sido postulada por Lessing, Mendelssohn y Jacobi ( $c f$. Solé 2011). Este paréntesis en el texto fichteano es fundamental para la interpretación que deseo defender en este artículo. Volveré sobre este punto al final.

20 GA I,2, p. 263. FDC, p. 20.

21 Según Vaysse, por ser una trasgresión de los límites del Yo soy, el spinozismo es el único sistema filosófico que vale la pena refutar. La refutación es, precisamente, la posición del primer principio de la Doctrina de la ciencia (cf. Vaysse 1994, p. 74). 
completamente incondicionado y no determinable por algo más elevado». ${ }^{22}$ La Doctrina de la ciencia es, pues, un sistema de filosofía crítica que procede de modo consecuente a partir de ese primer axioma. La filosofía dogmática, en cambio, pone como lo más elevado «algo idéntico y opuesto al Yo en sí»», ${ }^{23}$ que Fichte presenta como «el concepto, pretendidamente superior, de cosa (Ens)» que es puesto de manera arbitraria como lo absolutamente supremo. Por lo tanto, la diferencia entre ambos reside en que «en el sistema crítico la cosa es aquello que es puesto en el Yo; en el sistema dogmático, es aquello en que el mismo Yo es puesto». ${ }^{24} \mathrm{El}$ tercer principio de la Doctrina de la ciencia que Fichte viene de deducir y según el cual el Yo y el No-Yo limitados son puestos por el Yo en el Yo, permite entonces determinar más exactamente la diferencia entre ambos sistemas filosóficos. Se trata, básicamente, de una divergencia en la manera en que cada uno comprende la estructura de lo real.

En este sentido, el sistema de Spinoza, presentado ahora como «el producto más consecuente del dogmatismo, en la medida en que éste puede ser consecuente», ${ }^{25}$ es caracterizado como un sistema trascendente, porque el Yo es puesto en la cosa. El criticismo, por el contrario, es el sistema auténticamente inmanente, en el que todo -incluida la cosa- es puesto en el Yo.

Esta cuarta tesis acerca del spinozismo, que lo presenta como trascendente por hacer del No-Yo el principio fundamental, y la explicación que Fichte ofrece para defender esta lectura, se contrapone a la primera tesis interpretativa que había expuesto al final del $§ 1$ y, en mi opinión, la resignifica radicalmente. En realidad, Spinoza no logra ir más allá del Yo, sino que permanece indefectiblemente en el segundo principio de la Doctrina de la ciencia. Es en este sentido que Fichte reconoce que «el dogmatismo en general no es de ninguna manera lo que pretende ser» ${ }^{26}$ Esta afirmación, a diferencia de lo que aparenta ser, no constituye una crítica sino una reivindicación del dogmatismo -y eminentemente, del spinozismo-. "[L]e habríamos causado agravio (unrecht getan haben) con nuestras precedentes conclusiones», escribe Fichte, y advierte que si el dogmático se apropia de ellas, «se agravia a sí mismo (sich selbst unrecht thut)». ${ }^{27}$ Fichte explica por qué esto es así. «En verdad», escribe, «su unidad suprema no puede ser otra que la de la conciencia y su cosa es el sustrato de la divisibilidad en general o de la sustancia suprema, en la cual el Yo y el No-Yo (la inteligencia y la extensión, en Spinoza) son

22 GA I,2, p. 279. FDC, p. 32.

23 Ibid.

24 Ibid.

25 GA I.2, p. 280. FDC, p. 32.

26 GA I,2, p. 281. FDC, p. 33.

27 Ibid. 
puestos». ${ }^{28}$

El dogmatismo parece buscar un fundamento más allá del Yo absoluto. Pero en realidad, jamás logra sobrepasarlo y «allí donde va más lejos, como en el sistema de Spinoza», sostiene Fichte, «llega hasta nuestros principios segundo y tercero, pero no hasta el principio primero absolutamente incondicionado». ${ }^{29}$ Spinoza, el más coherente de todos los pensadores dogmáticos, solo logró elevarse hasta el segundo y tercer axioma de la Doctrina de la ciencia. Esta quinta tesis interpretativa acerca del spinozismo sostiene, por lo tanto, que el auténtico principio de la filosofía permaneció desconocido para él. «Estaba reservado a la filosofía crítica dar este último paso y consumar así la ciencia», ${ }^{30}$ concluye Fichte.

Así entendidos, la diferencia entre criticismo y spinozismo no reside en una auténtica divergencia respecto de sus principios; y la oposición planteada al final del $\S 1$ parece esfumarse. Fichte admite que ambos buscan la unidad suprema y que ambos -aunque Spinoza no lo sepa- son impulsados por una exigencia práctica. La diferencia reside entonces en que Spinoza solamente logra llegar al segundo y tercer principio, mientras que la Doctrina de la ciencia da un paso más y alcanza el Yo absoluto. El spinozismo no puede ser considerado por Fichte, entonces, como un sistema falso, como una alternativa totalmente opuesta a la suya propia, sino como un sistema incompleto, que únicamente la Doctrina de la ciencia logra consumar. Creo que así hay que leer lo que resta de este párrafo:

La parte teórica de nuestra Doctrina de la Ciencia, desarrollada solo a partir de los dos últimos principios, dado que aquí el primero sólo tiene un valor regulativo, es efectivamente, como se mostrará a su tiempo, el spinozismo sistemático. Solamente el Yo de cada cual es la única sustancia suprema. Pero nuestro sistema añade una parte práctica que fundamenta y determina a la primera, acaba así toda la ciencia y agota todo lo comprendido en el espíritu humano; de este modo el entendimiento humano común (den gemeinen Menschenverstand), vilipendiado por toda la filosofía pre-kantiana, separado al parecer de la filosofía por nuestro sistema teórico sin la menor esperanza de reconciliación (Versöhnung), será otra vez reconciliado (wieder aussöhnt) con ella. ${ }^{31}$

El spinozismo se revela aquí como un momento de la Doctrina de la ciencia: la parte teórica que considera al mundo como algo dado independientemente de la acción del sujeto, como algo inmodificable y regido 
según leyes necesarias e inmutables. El punto de vista de Spinoza, que es el de todo filósofo dogmático que desee ser coherente, es incorporado al sistema fichteano como una de sus partes, como su parte teórica. La Doctrina de la ciencia completa esta visión determinista de la realidad con la parte práctica que pone en evidencia que toda la realidad se fundamenta en la acción libre del Yo absoluto. De este modo, la Doctrina de la ciencia constituye la vía para lograr una ansiada reconciliación entre dos facultades humanas que, hasta ese momento, habían sido consideradas como incompatibles.

\section{LA DOCTRINA DE LA CIENCIA COMO RECONCILIACIÓN}

En el párrafo que acabo de citar, Fichte presenta a la Doctrina de la ciencia como el sistema que permite la reconciliación de la filosofía con una facultad humana que, según la presenta, había sido menospreciada por los pensadores anteriores a Kant: el entendimiento humano común (gemeiner Menschenverstand). La Doctrina de la ciencia no se queda únicamente con su parte teórica, sino que añade una parte práctica que muestra que es el Yo el que pone al No-Yo, lo limita, lo determina. Por lo tanto, lo que Fichte sugiere aquí es que aquello que el entendimiento humano común afirma y la especulación filosófica niega, aquello que la parte práctica de la Doctrina de la ciencia enseña, es la libertad: la posibilidad de que el Yo transforme el mundo mediante una acción moral.

Pocas páginas más adelante, ya instalado en el desarrollo de la parte teórica del sistema y luego de la deducción de la categoría de cualidad, Fichte vuelve a abordar la oposición entre criticismo y dogmatismo, esta vez en términos de idealismo y realismo. Nuevamente, habla de Spinoza.

La verdadera disputa entre el realismo y el idealismo, sostiene, es determinar el camino que se debe seguir para explicar la representación. Si se afirma que el No-Yo es la causa de la representación, entonces se transforma al No-Yo en el fundamento real de todo - «él es absolutamente lo que es porque es (el fatum de Spinoza)»-y al Yo en un mero accidente suyo. Esta posición es denominada aquí «spinozismo material». Se trata de un «realismo dogmático» que es nuevamente caracterizado como un sistema «que supone la ausencia de la abstracción más alta posible, la del No-Yo, y que carece por completo de fundamento, puesto que no establece el fundamento último.»» ${ }^{32}$

Al realismo dogmatico o spinozismo material Fichte opone el «idealismo dogmático», que explica la representación únicamente a partir del Yo. El problema con esta posición es, según Fichte, que el No-Yo se transforma en un mero fundamento ideal de la representación y fuera de ella carece de realidad: «no es sustancia, no es nada que exista para sí, puesto absolutamente, sino 
que solo es un mero accidente del Yo». ${ }^{33}$ Por lo tanto, si bien este idealismo dogmático ha emprendido la más alta abstracción y está fundado plenamente, le es imposible indicar el fundamento para la limitación de la realidad en el Yo y esto conduce a un subjetivismo inaceptable.

La verdadera cuestión disputada del realismo y del idealismo, resume Fichte, es determinar el camino que se debe seguir para explicar la representación. El problema es que es imposible decidir qué camino tomar si permanecemos en la parte teórica de la Doctrina de la ciencia. Aquí, escribe Fichte, «estos dos caminos son juntos; bajo cierta condición se está obligado a seguir uno, y bajo la condición opuesta, el otro; y así la razón humana, es decir, toda razón finita, se pierde en una contradicción consigo misma y queda encerrada en un círculo.» ${ }^{34}$

Para superar esta contradicción Fichte toma el camino del idealismo -el Yo puro no se puede eliminar- pero no dogmáticamente. Fichte presenta su idealismo como práctico, un idealismo «que no determina lo que es sino lo que debe ser». ${ }^{35} \mathrm{El}$ idealismo práctico pone el fundamento en el Yo «como debiendo contener en sí mismo el fundamento de la existencia del No-Yo que aminora la actividad del Yo inteligente $[\ldots] \gg{ }^{36}$ De esta manera, Fichte logra superar la posición determinista del spinozismo material o realismo dogmático propia de la perspectiva teórica, y afirmar que el fundamento de todo lo real es un Yo absoluto, una pura actividad libre de ponerse a sí mismo, y oponerse un mundo.

Esta contraposición entre determinismo y libertad, entre razón teórica y creencia práctica, había sido planteada por Fichte en un fragmento escrito en 1790 y publicado póstumamente como Algunos aforismos sobre religión y deísmo ${ }^{37}$ Este fragmento, que es el testimonio principal de sus convicciones juveniles, presenta con gran patetismo el conflicto insalvable entre los resultados de la especulación y las exigencias del corazón. La razón prueba la existencia de una divinidad eterna, imperturbable, que produce el mundo a partir de su pensamiento e impone un orden causal inmutable según el cual todo cambio en el universo tiene una causa suficiente y necesaria. El corazón humano, por el contrario, requiere de un Dios compasivo, capaz de atender a las súplicas de los hombres y modificar su plan en virtud de ellas, un Dios

33 Ibid.

34 GA I,2, p. 310. FDC, p. 58.

35 Ibid.

36 Ibid.

37 Fue publicado por el hijo de Fichte, Immanuel Hermann, primero en 1831, en la segunda parte de un libro titulado Johann Gottlieb Fichte's Leben und litterarischer Briefwechsel (pp. 18-25) y luego en el V tomo de las Sämtliche Werke, de 1845, pp. 1-8. En la edición crítica: GA II,1, pp. 287-291. 
antropomórfico al que se puede recurrir en busca de consuelo y salvación. Los seres humanos se encuentran, pues, desgarrados entre sus sentimientos y sus convicciones, entre la religión y el deísmo, entre el Dios del corazón que garantiza la libertad humana y el Dios del entendimiento que impone un determinismo inalterable. Así presentadas, estas posiciones no tienen nada en común. El deísmo no refuta ni niega al sentimiento religioso; pero tampoco lo reemplaza, pues no brinda a los hombres ningún consuelo. La religión del corazón no puede ser entendida ni demostrada, sólo puede ser sentida.

El joven Fichte ve al ser humano como un ser desgarrado, escindido entre la certeza de la especulación y la firmeza del sentimiento, oscilante entre la convicción de vivir en un mundo regido por una necesidad inamovible y el sentimiento de que es posible modificar el curso de los acontecimientos gracias a la propia libertad. Fue el encuentro con la Crítica de la razón práctica de Kant lo que logró poner fin a la angustiosa situación en que Fichte parece describirse a sí mismo en este fragmento, mostrándole cuál era el camino a seguir.

La cuestión del conflicto entre la razón y la fe, que ciertamente constituye uno de los tópicos característicos de la Ilustración alemana, ${ }^{38}$ había sido reavivada a finales del siglo XVIII por la célebre Polémica del spinozismo, que había tomado estado público en 1785con la aparición de las Cartas sobre la doctrina de Spinoza de F. H. Jacobi, reeditadas con abundantes añadidos en $1789 .{ }^{39}$ Contra la posición racionalista de Mendelssohn y la Ilustración berlinesa, Jacobi afirma allí que la pretensión de demostrarlo todo conduce a la anulación de la libertad, a la negación del verdadero Dios y a la aniquilación del mundo. Sin embargo, Jacobi sostiene que los seres humanos poseen una certeza inmediata, provista por la fe o creencia, que les hace imposible dudar de la existencia de un Dios bueno y creador, de la libertad del alma y de la existencia del mundo. Su propuesta consiste, pues, en abandonar la filosofía, cuyo resultado más coherente y perfecto es, según Jacobi, el sistema de Spinoza, mediante un salto mortal, para instalarse en el ámbito de la fe.

Dado el amplio conocimiento que Fichte poseía de las discusiones filosóficas del momento, es de suponer que estaba al tanto de los pormenores de la Polémica del spinozismo. ${ }^{40} \mathrm{Su}$ hijo Immanuel Hermann llega incluso a afirmar que la posición determinista de su padre expuesta en los Aforismos... toma como modelo al sistema de Spinoza. ${ }^{41} \mathrm{Si}$ bien este fragmento no

38 Cf. Serrano 2004, p. 13.

39 Véase Jacobi 1785. Traducción al castellano: Jacobi 2013. Acerca de la recepción de Spinoza en Alemania durante el siglo XVIII y la Polémica del spinozismo, véanse, entre otros: Bell 1984; Otto 1994; Scholz 1916; Tavoillot 1996; Timm 1974; Solé 2011 y 2013.

40 Esto lo reconocen todos los especialistas. $C f$. Lauth 1978, p. 28.

41 Fichte; I. H. 1845, p. VI. A partir de esta afirmación y del retrato del joven Fichte 
hace mención explícita ni a Spinoza ni a la polémica iniciada por Jacobi, la terminología utilizada pocos años después, en la GWL sí parece remitir claramente a ésta última. En efecto, cuando Fichte señala que su Doctrina de la ciencia logra consumar la filosofía, superar el dogmatismo y afirmar la libertad, habla de una reconciliación entre la filosofía y el entendimiento humano común -facultad a la que, en el contexto de la Polémica del spinozismo, Mendelssohn había recurrido para rechazar el ataque de Jacobi contra la razón especulativa.

Tanto en una de sus cartas a Jacobi como en su última obra sistemática publicada, las Horas matinales, Mendelssohn rechaza la exhortación a abandonar la filosofía racionalista, pero reconoce que la especulación tiende a perderse en sus derivas abstractas y puede conducir a resultados inadmisibles. Propone entonces un método de orientación, según el cual el sano entendimiento humano, entendimiento humano común o bon sens una facultad presente en todo ser humano que asegura la certeza de la existencia de Dios, el alma y la libertad, debe funcionar como una guía para que la especulación no se extravíe en las sutilezas del razonamiento filosófico. ${ }^{42}$

Las dificultades motivadas por la introducción de este sano entendimiento humano o sentido común, cuyo vínculo con la razón y cuya naturaleza propia no quedaban del todo claros, fueron puestas en evidencia en el desarrollo de la Polémica tanto por Thomas Wizenmann ${ }^{43}$ como por Kant, en el artículo de 1786, titulado «¿Qué significa orientarse en el pensamiento?». ${ }^{44}$ Kant pretende realizar una defensa de Mendelssohn, pero termina acusándolo, al igual que a Jacobi, de rebajar la razón y poner por sobre ella una fuente irracional de conocimiento. Su solución, que se encontraba ya esbozada en la Crítica de la razón pura, y que desarrolló luego más extensamente en la segunda Crítica, es su doctrina de la fe racional en Dios, que carece de fundamentos objetivos - no es conocimiento- pero posee suficientes fundamentos racionales subjetivos: las exigencias de la razón en su uso práctico.

\section{Spinoza en Fichte. Conclusión}

El análisis de la interpretación que hace Fichte de Spinoza en la GWL estableció que el spinozismo es considerado allí como el máximo representante de una posición que debe ser reconciliada con otra y no como una doctrina

ofrecido por Ludwig Noack, se instaló el tópico de que Fichte, en su juventud, habría adherido al spinozismo ( $c f$. Noack 1862, pp. 30-31). Esta posición ha sido rechazada por la mayoría de los especialistas ( $c f$. Lauth 1978, pp. 28 y ss).

42 Véase Mendelssohn 1785 y 1786.

43 Véase Wizenmann 1786.

44 Véase Kant 1786. 
a refutar. El spinozismo es para Fichte una filosofía determinista, resultado de la perspectiva teórica. Únicamente el idealismo práctico fichteano logra completarla, mediante una parte práctica que establece la libertad como fundamento absolutamente primero y originario de lo real.

Esta aparente oposición entre determinismo y libertad, que la Doctrina de la ciencia logra reconciliar remite, según la lectura que propuse aquí, a una problemática más amplia: al problema de la oposición entre la razón y la fe. Siendo uno de los temas que preocupó a los ilustrados alemanes, esta cuestión fue revitalizada por la Polémica del spinozismo, en el contexto de la cual Spinoza es señalado por Jacobi como el máximo representante de la filosofía racionalista y determinista. Este conflicto es, asimismo, el tema central de los Aforismos... que Fichte escribió 1790, donde plantea la oposición en términos de los resultados del uso teórico de la razón y las exigencias prácticas del sentimiento.

Ciertamente, hay que matizar la afirmación de Immanuel Hermann acerca de las convicciones spinozianas de su padre durante su juventud. No hay indicios que permitan sostener que al momento de escribir los Aforismos..., Spinoza es el modelo sobre el cual se traza la posición determinista y deísta -la cual parece más bien remitir a la doctrina de Leibniz y Wolff- ${ }^{45}$ De hecho, tal como señala Lauth, a partir de algunos testimonios textuales se sabe que Fichte se dedicó al estudio de Spinoza recién en el otoño de 1793, mientras se encontraba en Zürich, momento en el que también tuvo la posibilidad de discutir con Lavater el contenido de las Cartas... de Jacobi. ${ }^{46}$

Pero cuando en el semestre de invierno de 1794 Fichte plasma su sistema en los apuntes para sus alumnos de la Universidad de Jena, que luego recopila y publica bajo el título de GWL, Spinoza sí aparece como el representante más coherente de esa posición que en los Aforismos había presentado como propia de la especulación y que, en ese momento, había delineado a partir de elementos del sistema leibniz-wolffiano.

El hecho de que en el texto de la GWL se afirme explícitamente, remitiendo a Salomon Maimon, que el sistema de Leibniz, «rigurosamente desarrollado», ${ }^{47}$ no difiere del spinozismo, abona esta lectura. Esta referencia muestra que, según Fichte en 1794, la doctrina leibniziana coincide esencialmente con la spinoziana en sus principios y ésta última representa su desarrollo auténticamente riguroso. De modo que, si bien es factible que Spinoza no haya sido el modelo a partir del cual Fichte construyó la posición determinista expuesta en los Aforismos de 1790, cuatro años más tarde, al 
exponer por primera vez públicamente su Doctrina de la ciencia, Fichte puede conectar esa visión determinista con el nombre de Spinoza, que se le presenta ahora, luego haberlo estudiado durante el otoño de 1793 en Zürich, como la versión más coherente de los sistemas que buscan explicar la experiencia mediante un principio diferente del Yo soy.

El camino para salir del dilema que lo aquejaba desde su juventud -la incompatibilidad entre un universo que se comporta de manera determinista y el innegable sentimiento de la propia libertad- se lo enseñó, según el testimonio conocido del propio Fichte, la Crítica de la razón práctica de Kant. ${ }^{48}$ Pero, según se sabe, Fichte consideró que la posición kantiana carecía aún de la sistematicidad requerida para ser una auténtica ciencia. ${ }^{49} \mathrm{La}$ Doctrina de la ciencia, que su autor presenta usualmente como «el primer sistema de la libertad» constituye, así, la solución fichteana a la preocupación de la época, planteada de manera radical durante la Polémica del el spinozismo.

Creo que este análisis de la figura de Spinoza en la GWL junto con la consideración del contexto problemático amplio en el que surge la Doctrina de la ciencia permite explicar por qué Spinoza necesariamente debía ocupar un lugar privilegiado en la argumentación de esa obra. Spinoza no es su principal adversario, contra el cual se alza el sistema fichteano. Su principal adversario es Jacobi, que sostiene la imposibilidad de producir un sistema filosófico que sea científico y que al mismo tiempo permita conservar la certeza de la propia libertad. Así, a pesar de que aparentemente se da una importante coincidencia en sus interpretaciones del spinozismo, existe una diferencia fundamental que indica exactamente cuál es el punto de la discusión entre ellos.

Según Jacobi, el spinozismo es totalmente coherente y no puede ser refutado, es el producto más perfecto de la razón y la única manera de deshacerse de él es abandonando por completo la filosofía. Según Fichte, el spinozismo es coherente e irrefutable, pero no es completo: representa únicamente la parte teórica de la Doctrina de la ciencia erigida sobre el NoYo, carece del auténtico fundamento que sólo ésta puede aportar y que permite construir su parte práctica. Se trata, pues, de completar el spinozismo, no de refutarlo. Porque completar el sistema de Spinoza es la vía para refutar a Jacobi y desarticular la disyuntiva excluyente planteada por él entre el saber racional y la fe irracional.

La respuesta de Fichte a Jacobi es, por lo tanto, la construcción de un sistema de la libertad que no refuta a Spinoza sino que lo incluye y lo supera.

48 Véase la carta de Fichte a Weisshun de agosto o septiembre de 1790 (GA III.1, p. 167). Véase también la Carta a su prometida, Johanna Rahn, del 5 de septiembre de 1790 en GA III.1, pp. 169 y ss..

49 Véase Fichte 1794. En español: Fichte 1963. 
Esta es, quizás, la manera en que hay que entender que Fichte afirme, tanto en 1795 como hacia el final de su vida, que el spinozismo es la mejor vía de acceso a la Doctrina de la ciencia.

\section{REFERENCIAS BIBLIOGRÁFICAS}

AAVV 2013: El ocaso de la Ilustración. La Polémica del spinozismo. Selección, traducción, estudio preliminar y notas de M. J. Solé. Bernal: Editorial de la Universidad de Quilmes.

AMRIN, F. 2015: «The magic formula we all seek: Spinoza + Fichte $=\mathrm{x}$ ». En Lundy, C. y Voss, D. (eds): At the Edges of Thought: Deleuze and Post-Kantian Philosophy. Edinburgh: Edinburgh University Press. Pp. 168-189.

BEISER, F. 2015: «La paradoja de la metafísica romántica». En Análisis. Revista de investigación filosófica, vol. 2, n. ${ }^{\circ}$ 2. Pp. 255-281.

BELL, David 1984: Spinoza In Germany From 1670 To The Age Of Goethe. Londres: University of London.

FICHTE, Johann Gottlieb 1794: Über den Begriff der Wissenschaftslehre oder der sogenannten Philosophie. Weimar: Verlage des Industrie Comptoirs.

, 1794/5: Grundlage der gesamten Wissenschaftslehre. Leipzig: Cristian Ernst Gabler.

, 1845: Sämtliche Werke, tomo V. Ed. por I. H. Fichte. Berlin: Verlag von Veit und Comp.

, 1962 y ss.: Gesamtausgabe der Bayerischen Akademie der Wissenschaften. 40 tomos. Ed. por Reinhard Lauth, Erich Fuchs y Hans Gliwitzky. Stuttgart-Bad Cannstatt: Frommann-Holzboog [GA]

. 1975: Fundamentación de toda la Doctrina de la ciencia. Trad., introducción y notas de J. Cruz Cruz. Buenos Aires: Aguilar. [FDC]

, 1963: Sobre el concepto de la Doctrina de la Ciencia. Trad. B. Navarro. México: UNAM.

FICHTE, Immanuel Herman 1831: Johann Gottlieb Fichtes Leben und litterarischer Briefwechsel. Parte II. Sulzbach: Seidel.

, 1845: «Vorrede des Herausgebers» en Fichte, J. G.: Sämtliche Werke, tomo V. Ed. por I. H. Fichte. Berlin: Verlag von Veit und Comp.

FÖRSTER, E. y MELAMED, Y. (eds.) 2012: Spinoza and German Idealism. Cambridge: Cambridge University Press.

GAUDIO, Mariano 2015: «¿Spinoza en Fichte? Elucubraciones sobre el dogmatismo, la libertad y la ley jurídica». En Solé, M. J. (ed.): Spinoza en debate. Buenos Aires: Miño y Dávila. Pp. 131-154.

GODDARD, Jean-Christophe 2005: «Dans quelle mesure Fichte est-il spinoziste?», En Bouton, Cristophe (ed.): Dieu et la nature. La question du panthéisme dans 
l'idéalisme allemand. Hildesheim: Georg Olms Verlag.

, 2006: «Idéalisme et spinozisme chez Fichte». En Ong-Van-Cung, Kim Sang: Idée et idealisme. Recherches sur l'idéalisme et le romantisme allemands. Paris: Vrin.

GUILHERME, Alexandre 2009 : Fichte and Schelling: The Spinoza Connection. Saarbrücken: VDM Verlag.

HAAG, Johannes 2012: «Fichte on the consciousness of Spinoza's God». En Förster, E. y Melamed, Y. (eds.): Spinoza and German Idealism. Cambridge: Cambridge University Press. Pp. 100-120.

HAMMACHER, K. 1992: «Fichte und Spinoza», en Walther, M., Spinoza und der deutsche Idealismus. Würzburg: Königshausen und Neumann. Pp. 81-99.

HENRICH, Dieter 2003: Between Kant and Hegel. Lectures on German Idealism. Cambridge/ Massachusetts, London: Harvard University Press.

IVALDO, Marco 1992: «Transzendentalphilosophie und "realistische" Metaphysik: Das Fichtesche Spinoza-Verständnis». En Walther, M., Spinoza und der deutsche Idealismus. Würzburg: Königshausen und Neumann. Pp. 59-79.

JACOBI, Friedrich Heinrich 1785: Über die Lehre des Spinoza in Briefen an den Herrn Moses Mendelssohn. Breslau: Gottlieb Löwe.

,2013: Cartas sobre la doctrina de Spinoza al Sr. Moses Mendelssohn. En AAVV, El ocaso de la Ilustración, op. cit.

, 1998: Werke. Gesamtausgabe. Tomo I.1. Ed. por Klaus Hammacher y Walter Jaeschke. Hamburg: Meiner/Frommann-Holzboog.

KANT, Immanuel 1786: «Was heißt: sich im Denken Orientieren?». En Berlinische Monatsschrift, pp. 304 a 329.

,2013, «¿Qué significa orientarse en el pensamiento?» en AAVV, El ocaso de la Ilustración, op. cit.

LAUTH, Reinhard 1978: «Spinoza vu par Fichte». En Archives de Philosophie 41, pp. 27-48.

MENDELSSOHN, Moses1785: Morgenstunden oder Vorlesungen über das Daseyn Gottes. Berlín: Christian Friedrich Voss.

, 1786: An die Freunde Lessings, Ein Anhang zu Herrn Jacobis Briefwechsel über die Lehre des Spinoza. Berlín: Christian Friedrich Voss.

, 2013a: A los amigos de Lessing. En AAVV 2013: El ocaso de la Ilustración, op. cit.

, 2013b: Horas matinales. Selección. En AAVV 2013: El ocaso de la Ilustración, op. cit.

NOAK, Ludwig 1862: Johann Gottlieb Fichte nach seinem Leben, Lehren und Wirken. Leipzig.

OTTO, Rudiger 1994: Studien zur Spinozarezeption in Deutschland im 18. Jahrhundert. Frankfurt a.M.: Peter Lang. 
RIVERA DE ROSALES, J. y Cubo, O. (ed.) 2009: La polémica sobre el ateísmo, Fichte y su época. Madrid: Dykinson.

SCHOLZ, Heinrich 1916: Die Hauptschriften zum Pantheismusstreit. Berlín: Reuther \& Richard.

SERRANO, Vicente 2004: Metafísica y filosofía trascendental en el primer Fichte. Valencia: Editorial UPV.

SOLÉ, María Jimena 2011: Spinoza en Alemania (1670-1789). Historia de la santifcación de un filósofo maldito. Córdoba: Brujas. , 2013: «Estudio preliminar. La Polémica del spinozismo. Antecedentes, desarrollo y consecuencias», en AA.VV. El ocaso de la Ilustración, op. cit.

TAVOILLOT, H-P. 1996 : Le Crépuscule des Lumières. Les documents de la Querelle du panthéisme. 1780-1789. París: CERF.

TIMM, Hermann 1974: Gott und die Freiheit. Studien zur Religionsphilosophie der Goethezeit.I: Die Spinozarenaissance. Frankfurt am Main: Vittorio Klostermann.

TOSEL, André, Moreau, Pierre-François y Salem, Jean (dir), Spinoza au XIXe siècle, Paris, Publications de la Sorbonne, 2008.

VAYSSE, J.-M. 1994 : Totalité et Subjectivité. Spinoza dans l'Idéalisme Allemand. Paris: Vrin.

WIZENMANN, Thomas 1786: Die Resultate der Jacobischen und Mendelssohnschen Philosophie, kritische untersucht von einem Freywilligen. Leipzig: Göschen.

, 2013: Los resultados de las filosofías de Jacobi y de Mendelssohn examinados críticamente por un voluntario. Selección, en AA.VV., El ocaso de la Ilustración, op. cit.

María Jimena Solé es Investigadora del CONICET Y docente de Historia de la Filosofía Moderna del Departamento de Filosofía de la Facultad de Filosofía y Letras de la Universidad de Buenos Aires.

Lineas de Investigación:

Teoría del conocimiento, metafísica y filosofía política en la Ilustración e Idealismo en Alemania. Historia de la filosofía y recepción del spinozismo en el siglo XVIII.

Publicaciones recientes:

(2016): «Especulación, sentimiento y escisión en el joven Fichte. Análisis de sus Aforismos sobre religión y deísmo», Veritas. Revista de Filosofía y Teología 35: $59-80$.

LERUSSI, Natalia y SOLÉ, María Jimena (eds.) 2016: En busca del Idealismo. Las transformaciones de un concepto. Buenos Aires: RAGIF Ediciones.

Correo electrónico: jimenasole@filo.uba.ar 